\title{
A prospective, randomized, double blind, systemic controlled trial to compare analgesic efficacy of clonidine and fentanyl in supraclavicular block with $0.75 \%$ ropivacaine
}

\author{
Muni Ram Meena ${ }^{1}$, Hemraj Tungria ${ }^{2, *}$, Garima Tyagi ${ }^{3}$, Anisha Banu ${ }^{4}$, Lalit Kumar Raiger ${ }^{5}$ \\ 1,2 Assistant Professor, ${ }^{3}$ Junior Consultant, ${ }^{4}$ Senior Resident, ${ }^{5}$ Senior Professor, Dept. of Anaesthesia, ${ }^{\mathbf{1}, 2,4,5}$ RNT Medical College, \\ Udaipur, Rajasthan, ${ }^{3}$ Narayana Multispeciality Hospital, Jaipur, Rajasthan, India
}

*Corresponding Author: Hemraj Tungria

Email: htungaria@gmail.com

Received: $8^{\text {th }}$ August, 2018

Accepted: $28^{\text {th }}$ August, 2018

\begin{abstract}
Introduction and Object: Fentanyl and clonidine mostly used as adjuvant to improve quality and duration of nerve block. In present study we compared clonidine and fentanyl perineurally and systemically in Supraclavicular Brachial plexus block.

Materials and Methods: Sixty eight patients were randomly assigned into four equal groups, scheduled for upper limb surgery. They received the drugs in Supraclavicular block and intravenous route as below: Group A: $24 \mathrm{ml} 0.75 \%$ ropivacaine $+1 \mathrm{ml}$ fentanyl $(50 \mu \mathrm{g} / \mathrm{ml})+5 \mathrm{ml}$ normal saline in block and $1 \mathrm{ml}$ normal saline intravenously. Group B: $24 \mathrm{ml} 0.75 \%$ ropivacaine $+6 \mathrm{ml}$ normal saline in block, and $1 \mathrm{ml}$ fentanyl $(50 \mu \mathrm{g} / \mathrm{ml})$ intravenously. Group C: $24 \mathrm{ml} 0.75 \%$ ropivacaine $+1 \mathrm{ml}$ clonidine $(150 \mu \mathrm{g} / \mathrm{ml})+5 \mathrm{ml}$ normal saline in block, and $1 \mathrm{ml}$ normal saline intravenously. Group D: $24 \mathrm{ml} 0.75 \%$ ropivacaine $+6 \mathrm{ml}$ normal saline in block, and $1 \mathrm{ml}$ clonidine $(150 \mu \mathrm{g} / \mathrm{ml})$ intravenously.

Results: Onset of sensory and motor block was significantly earlier in Group C (12.47 \pm 2.57 min \& $18.00 \pm 3.46$ min) than in Group A $(14.65 \pm 3.41 \mathrm{~min} \& 19.94 \pm 2.61 \mathrm{~min})$ respectively $(\mathrm{p}<0.05)$. Mean duration of analgesia was comparable $(\mathrm{p}>0.05)$ between Group A (7.41 $\pm 0.94 \mathrm{hrs})$ and Group B (7.35 $\pm 0.93 \mathrm{hrs})$ while it was prolonged in Group C (8.94 $\pm 0.97 \mathrm{hrs})$ than Group D $(8.12 \pm 1.22 \mathrm{hrs})(\mathrm{p}<0.003)$ and clonidine had longer mean duration of analgesia $(8.94 \pm 0.97 \mathrm{hrs})$ as compared to fentanyl ( $7.41 \pm 0.94 \mathrm{hrs})$ when both were administered perineurally $(\mathrm{p}<0.001)$.

Conclusion: Fentanyl perineurally or systemically administered have comparable results while perineural clonidine offered prolonged duration of analgesia better than when it was used intravenously suggesting its local action.
\end{abstract}

Keywords: Supraclavicular Block, Ropivacaine, Clonidine, Fentanyl.

\section{Introduction}

For upper limb surgeries, supraclavicular brachial plexus block is used mostly as it provides safe, reliable and dense anaesthesia for surgery and also ensures adequate postoperative analgesia. However, long lasting surgeries compelled anaesthesiologist to search for various adjuncts to regional nerve blocks which can prolong the duration of anaesthesia with lesser side effect.

Opioids like fentanyl has been successfully used as adjuvant to local anesthetics in brachial plexus block due to rapid onset, and prolonged analgesia with side effects like: sedation, hypotension, pruritis and sympathomimetic effects postulate the possible mechanism of direct action on peripheral opioid receptor. Fentanyl may penetrate the nerve membrane and may act on dorsal horn and reported to have a local anaesthetic action. ${ }^{1}$

Clonidine, an $\alpha-2$ adrenergic agonist studied for preanaesthetic medication and as adjuvants to local anaesthetic for epidural, spinal and peripheral nerve block. A postulated mechanism for this is that clonidine blocks conduction of $\mathrm{C} \& \mathrm{~A}$ delta fibers and increases potassium conductance. Secondly, clonidine causes local vasoconstriction, thereby reducing vascular uptake of local anaesthestic from around the neural structure. ${ }^{2}$
However it is a topic of debate that fentanyl and clonidine given with local anaesthetic in regional nerve block enhances the block by acting perineurally or it is because of systemic absorption of fentanyl and clonidine administered in block.

This might be explained by administering the same dose of fentanyl and clonidine perineurally and systemically and finding out the differences in the quality of block.

Therefore, we designed this study to compare fentanyl $(50 \mu \mathrm{g})$ and clonidine $(150 \mu \mathrm{g})$ as an adjuvants and as an intravenous administration in supraclavicular plexus block with $0.75 \%$ ropivacaine.

\section{Materials and Methods}

The present study was conducted in tertiary care hospital, after hospital ethical committee's approval and informed and written consent from patients and relatives.

The study population includes patients with the age of 15 to $60 \mathrm{yrs}$, of both the sex, having ASA grading either I or II, posted for elective upper limb surgery.

Patient with sensitivity to local anesthetics, skin infection at needle insertion site, patients on anticoagulant drugs, pre-existing neurological deficits, COPD and chronic opioids user and patient refusal for the study were excluded from the study. 
Based on previous study (Baj et al $2013^{3}$ ), sample size of 15 patients was calculated after applying alpha error of 0.005 and power of study $90 \%$. We had taken 17 patients in each group for dropout compensation. So Sixty eight patients were randomly assigned into four equal groups using sequentially numbered, opaque sealed envelopes method.

Group A: Inj. ropivacaine $(0.75 \%) 24 \mathrm{ml}+1 \mathrm{ml}$ fentanyl $(50 \mu \mathrm{g} / \mathrm{ml})+5 \mathrm{ml}$ normal saline in Supraclavicular block; and $1 \mathrm{ml}$ normal saline intravenously.

Group B: Inj. ropivacaine $(0.75 \%) 24 \mathrm{ml}+6 \mathrm{ml}$ normal saline in Supraclavicular block; and $1 \mathrm{ml}$ fentanyl $(50 \mu \mathrm{g}$ $/ \mathrm{ml}$ ) intravenously.

Group C: Inj. ropivacaine $(0.75 \%) 24 \mathrm{ml}+1 \mathrm{ml}$ clonidine $(150 \mu \mathrm{g} / \mathrm{ml})+5 \mathrm{ml}$ normal saline in Supraclavicular block; and $1 \mathrm{ml}$ normal saline intravenously.

Group D: Inj. ropivacaine $(0.75 \%) 24 \mathrm{ml}+6 \mathrm{ml}$ normal saline in Supraclavicular block; and $1 \mathrm{ml}$ clonidine $(150 \mu \mathrm{g} / \mathrm{ml})$ intravenously.

Double blinding was done as follows;

' $\mathrm{X}$ ' anaesthetist prepared the drugs in two syringes, and it was lebelled as syringe ' $\mathrm{A}$ ' and ' $\mathrm{B}$ '

Syringe A; contained $1 \mathrm{ml}$ fentanyl $(50 \mu \mathrm{g})$ OR clonidine $(150 \mu \mathrm{g})$, added to $24 \mathrm{ml}$ of $0.75 \%$ ropivacaine as adjuvant and normal saline 5 or $6 \mathrm{ml}$ according to group assigned to make total $30 \mathrm{ml}$ volume in supraclavicular block

Syringe B; contained either $1 \mathrm{ml}$ fentanyl $(50 \mu \mathrm{g})$ or $1 \mathrm{ml}$ clonidine $(150 \mu \mathrm{g})$ or $1 \mathrm{ml}$ normal saline was given intravenously after 15 minute of block administration,

' $\mathrm{Y}$ ' anaesthetist who performed block was unaware of the drugs in syringes, and also performed intaoperative and postoperative monitoring. Another copy of group randomization was kept in sealed envelope and decoding was done at the end of study.

The patients were taken to operation theatre, all the basic monitoring i.e HR, non-invasive BP (NIBP),ECG etc were applied and after IV cannulation patients were positioned supine with the head turned opposite side, and arm placed medially towards the body. A point $1 \mathrm{~cm}$ above and at the junction of inner $2 / 3$ and outer $1 / 3$ of the clavicle was chosen to perform the block. It corresponds just posterior to the subclavian artery pulsation; which is lying in a plane just medial to the midpoint of the clavicle. After applying local anaesthesia with $2 \mathrm{ml}$ lignocaine (1\%), a 22 -gauge, $4 \mathrm{~cm}$ long hypodermic needle was directed just above and posterior to the subclavian artery pulse and directed caudally at a very flat angle against the skin. The needle was advanced and once paresthesia is encountered; then drug was injected as per group allocation with repeated aspiration.

After $5 \mathrm{~min}$ of drug injection onset of sensory and motor block was noted. Assessment of sensory block ${ }^{4}$ (Grade 0: Sharp pin felt, Grade 1: Analgesia, dull sensation felt; Grade 2: Anaesthesia, no sensation felt) was done at each minute in corresponding dermatomal areas of radial nerve, ulnar nerve, median nerve and musculocutaneous nerve till there was complete loss of sensation to pin prick. (Grade 2)

Motor block was assessed by a modified bromage scale on a 3-point scale 5 .

Grade 0: Normal motor function with full flexion and extension of elbow, wrist and fingers

Grade 1: Decreased motor strength with ability to move the fingers only

Grade 2: Complete motor block with inability to move the fingers.

Duration of sensory and motor blockade: was observed in postoperative room every hour till the recovery of sensory and motor blockade by an anesthesiologist who was blinded to the study groups.

Post operative pain was assessed using 10 point visual analog scale (VAS ${ }^{6}$ was as follows: ' 0 ' -no pain, and ' 10 '- maximum imaginable pain) every hour upto 12 hours. Patient was required to mark the $10 \mathrm{~cm}$ line at point that corresponds to the level of pain intensity he or she feels:

Both intraoperative and postoperative sedation was rated by using the 4 point sedation $\operatorname{score}^{7}$ : 0 - awake, 1 - drowsy, 2 - sleeping but arousable on verbal command, 3 - sleeping and arousable only on tactile stimulation and the end point of the study was time from performance of the block to onset of pain (ie. VAS $\geq 4$ ) and inj. Fentanyl $2 \mu \mathrm{g} / \mathrm{kg}$ intravenously was given as rescue analgesia or whenever patient demanded for it.

Postoperative vitals ( $\mathrm{HR}, \mathrm{SBP}, \mathrm{DBP}, \mathrm{SpO}_{2}$ ) were recorded at $0,15,30,45$ minute and there after every hour upto 12 hours.

The incidence of side effects (e.g. bradycardia, hypotention and sedation) was noted. Hypotension was considered when systolic pressure falls more than $30 \%$ from basal value or less than $90 \mathrm{~mm}$ of $\mathrm{Hg}$ and treated with IV fluids and inj. Mephentermine $6 \mathrm{mg}$ IV in incremental doses if needed. Bradycardia was considered when HR decreases by $20 \%$ from the basal value or it was less than 60 per min. It was treated with injection Atropine $0.6 \mathrm{mg}$ IV.

If pain occur during surgery, supplementation with $2 \mu \mathrm{g} / \mathrm{kg}$ fentanyl was done. Even after supplementation, if the pain persist it was treated as a failed block and general anaesthesia was given. These patients of failed block were excluded from the study.

\section{Statistical Analysis}

The data were analyzed by using computer software EPI info 6 SPSS12.0 for windows. Continuous variables were analyzed using, t-test while the chisquare test compared categorical variables. All analysis were two sided and a $\mathrm{P}$ value less than 0.05 was considered statistically significant. Data was reflected as Mean $\pm \mathrm{SD}$ or $\%$ of patients. 


\section{Results}

In present study, The patients in each group were demographically comparable with regard to age, sex, height, weight, ASA grading and found statistically insignificant $(\mathrm{P}>0.05$, Table 1$)$.

The mean duration of surgery was $55.88 \pm 15.02$, $61.17 \pm 15.66, \quad 59.70 \pm 15.85, \quad 54.70 \pm 18.40$ minute in group $\mathrm{A}, \mathrm{B}, \mathrm{C}$ and $\mathrm{D}$ respectively and was statistically nonsignificant ( $\mathrm{P}$ value 0.407). All the four groups in present study had comparable hemodynamic parameters.

Onset of sensory and motor block was earlier in perineural clonidine Group C $(12.47 \pm 2.57 \mathrm{~min}$ \& $18.00 \pm 3.46 \mathrm{~min})$ than in perineural fentanyl group A $(14.65 \pm 3.41 \mathrm{~min} \& 19.94 \pm 2.61 \mathrm{~min})$ respectively and it was statistically significant $(\mathrm{p}<0.05)$. Mean duration of analgesia when compared between fentanyl perineurally $(7.41 \pm 0.94 \mathrm{hrs})$ and intravenously ( $7.35 \pm 0.93 \mathrm{hrs})$ had comparable results $(\mathrm{p}>0.05)$ while it was prolonged in perineural clonidine group $(8.94 \pm 0.97$ $\mathrm{hrs})$ than intravenous clonidine group $(8.12 \pm 1.22 \mathrm{hrs})$ $(p<0.003)$ and clonidine had longer mean duration of analgesia $(8.94 \pm 0.97 \mathrm{hrs})$ as compared to fentanyl $(7.41 \pm 0.94 \mathrm{hrs})$ when both were administered perineurally, which was highly significant $(\mathrm{p}<0.001)$.

Mean VAS score was $1.76 \pm 1.27$ in group A, $1.86 \pm 0.12$ in group $\mathrm{B}, 1.33 \pm 0.22$ in group $\mathrm{C}$ and $1.65 \pm 0.14$ in group $\mathrm{D}$.

Adverse effects like nausea, vomiting and hypotension was noted in each group while sedation and bradycardia was observed in group $\mathrm{C}$ and $\mathrm{D}$, had no clinical as well as statistical significance.

Table 1: Group wise distribution of demographic and other data

\begin{tabular}{|c|c|c|c|c|c|}
\hline \multirow{2}{*}{\multicolumn{2}{|c|}{$\begin{array}{c}\text { Demographic and } \\
\text { other data }\end{array}$}} & \multicolumn{4}{|c|}{ Groups } \\
\hline & & Group A & Group B & Group C & Group D \\
\hline \multicolumn{2}{|c|}{ Age $($ Mean \pm SD) } & $34.88 \pm 13.20$ & $43.65 \pm 20.37$ & $34.76 \pm 13.24$ & $40.18 \pm 11.16$ \\
\hline \multicolumn{2}{|c|}{ Height (Mean \pm SD) } & $160.64 \pm 6.85$ & $162.32 \pm 6.63$ & $162.64 \pm 7.10$ & $163.35 \pm 6.12$ \\
\hline \multicolumn{2}{|c|}{ Weight (Mean \pm SD) } & $61.23 \pm 6.14$ & $62.47 \pm 6.11$ & $63.65 \pm 6.80$ & $63.12 \pm 6.52$ \\
\hline \multicolumn{2}{|c|}{ Duration $($ Mean \pm SD) } & $55.88 \pm 15.02$ & $61.17 \pm 15.66$ & $59.70 \pm 15.85$ & $54.70 \pm 18.40$ \\
\hline \multirow[t]{2}{*}{ Sex } & Male & $14(82.35 \%)$ & $14(82.35 \%)$ & $13(76.47 \%)$ & $13(76.47 \%)$ \\
\hline & Female & $3(17.65 \%)$ & $3(17.65 \%)$ & $4(23.53 \%)$ & $4(23.53 \%)$ \\
\hline \multirow[t]{2}{*}{ ASA Grade } & I & $15(88.2 \%)$ & $16(94.1 \%)$ & $16(94.1 \%)$ & $15(88.2 \%)$ \\
\hline & II & $2(11.8 \%)$ & $1(5.9 \%)$ & $1(5.9 \%)$ & $2(11.8 \%)$ \\
\hline
\end{tabular}

Table 2: Onset and duration of sensory and motor block among the groups

\begin{tabular}{|c|c|c|c|c|c|c|c|}
\hline \multirow{3}{*}{ Parameters } & \multicolumn{4}{|c|}{ Groups } & \multicolumn{3}{|c|}{$\begin{array}{l}\text { Significance } \\
\text { (P value) }\end{array}$} \\
\hline & Group A & Group B & Group C & Group D & & & \\
\hline & $($ Mean \pm SD $)$ & $($ Mean \pm SD $)$ & (Mean \pm SD) & $($ Mean \pm SD $)$ & $\mathbf{A} / \mathbf{B}$ & C/D & $\mathrm{A} / \mathrm{C}$ \\
\hline $\begin{array}{l}\text { Onset of Sensory block } \\
\text { (in min.) }\end{array}$ & $14.65 \pm 3.41$ & $13.76 \pm 3.58$ & $12.47 \pm 2.57$ & $13.00 \pm 2.29$ & 0.328 & 0.531 & 0.043 \\
\hline $\begin{array}{l}\text { Onset of Motor block } \\
\text { (in min.) }\end{array}$ & $19.94 \pm 2.61$ & $21.00 \pm 2.67$ & $18.00 \pm 3.46$ & $18.12 \pm 3.20$ & 0.125 & 0.890 & 0.019 \\
\hline $\begin{array}{l}\text { Duration of Sensory } \\
\text { block (in hrs) }\end{array}$ & $6.19 \pm 1.22$ & $5.86 \pm 0.51$ & $7.41 \pm 1.00$ & $6.56 \pm 0.72$ & 0.177 & 0.008 & 0.003 \\
\hline $\begin{array}{l}\text { Duration of Motor } \\
\text { block (in hrs) }\end{array}$ & $6.21 \pm 0.53$ & $6.17 \pm 0.72$ & $6.79 \pm 0.86$ & $6.03 \pm 0.69$ & 0.807 & 0.008 & 0.003 \\
\hline $\begin{array}{l}\text { Rescue analgesia (in } \\
\text { hrs) }\end{array}$ & $7.41 \pm 0.94$ & $7.35 \pm 0.93$ & $8.94 \pm 0.97$ & $8.12 \pm 1.22$ & 0.504 & 0.006 & 0.001 \\
\hline
\end{tabular}

\section{Discussion}

Opioids and $\alpha 2$ agonist have been used frequently as an adjuvants with local anaesthetic intrathecally, in epidural space as well as in various nerve blocks to ensure good peri-operative anaesthesia as well as analgesia without major side effect, but opinion differs on the side effect like nausea, vomiting, pruritus, bradycardia, hypotension, sedation etc. ${ }^{8}$ associated with these were due to systemic absorption of locally administered adjuvants or due to some other mechanism. So this study was planned to define effect of clonidine and fentanyl, when they were given with
$0.75 \%$ ropivacaine in Supraclavicular brachial plexus block perineurally and also intravenously in the same dose.

In our study onset of sensory and motor blockade was earlier in group C $(12.47 \pm 2.57$ and $18.00 \pm 3.46$ min) as compared to other groups. When a comparision done between group A and group B, it was statistically non significant ( $\mathrm{p}$ value 0.328 for sensory and 0.125 for motor onset). It meant that intravenous fentanyl did not have any significant effect on onset of action. Same result was found when group $\mathrm{C}$ and $\mathrm{D}$ were compared. ( $\mathrm{p}$ value 0.531 and 0.890 ). 
Group C had faster onset compared to group A. it might be explained by clonidine as a perineural adjuvant have synergistic action on $\mathrm{A}$ delta and $\mathrm{C}$ fibre with ropivacaine resulting in early onset of blockade compared to other groups.

So to conclude, intravenous administration of fentanyl and clonidine does not have significant effect on onset of sensory and motor block with ropivacaine in Supraclavicular block compared to their use as a perineural adjuvants.

These result also supported by a study done by Bedi et al (2017). ${ }^{9}$

The duration of sensory and motor blockade was highest in perineural clonidine group C $(7.41 \pm 1.00$ and $6.79 \pm 0.86 \mathrm{hrs}$ respectively) as compared to perineural fentanyl group A $(6.19 \pm 1.22$ and $6.21 \pm 0.53 \mathrm{hrs}$ respectively), and it was statistically significant ( $\mathrm{p}=$ 0.003 and $p<0.0474)$.

There was no statistically significant difference between perineural fentanyl group A and intravenous fentanyl group B, while difference was statistically significant on comparing perineural clonidine group $\mathrm{C}$ and intravenous clonidine group D ( $\mathrm{p}$ value 0.008 ). It shows that clonidine when given perineurally prolongs duration of block significantly than when given intravenously and this effect is mediated by local action rather than systemic as evidenced by our result.

The results of the present study are similar to those reported earlier studies by Baj et al (2013), ${ }^{3}$ Ahmed NU et al (2011), ${ }^{10}$ Kohli et al (2013), ${ }^{11}$ Jaiswal et al (2013) $)^{12}$ V. Bedi et al $(2017)^{9}$ who found that the significant prolongation of mean total duration of sensory and motor block occured in which clonidine given perineurally.

Time to first rescue analgesia (duration of analgesia) Mean duration of analgesia was longest in perineural clonidine group C $(8.12 \pm 1.22 \mathrm{hrs})$ in comparison to group A (statistically significant p value 0.001 ) and it might be due to that clonidine enhance sensory and motor nerve blockade by three possible mechanism: (1) clonidine block conduction of $\mathrm{C}$ and $\mathrm{A}$ delta fibers and increase potassium conductance and intensifies conduction block of local anaesthetics, (2) clonidine may cause local vasoconstriction thereby reducing vascular removal of local anaesthetic surrounding neural structures, and (3) primary spinal site of action of alpha 2 adrenergic agonist for analgesia and a mutifactorial mechanism of action enhancing peripheral or intraspinal blockade from local anaesthetics. ${ }^{13}$

Our findings correlated with those of Kulkarni et al. $(2012)^{14}$ and El Saied et al $(2000),{ }^{15}$ Bedi et al (2017). ${ }^{9}$

When compared, duration of analgesia of Group A (7.41 $\pm 1.00 \mathrm{hrs})$ from Group B $(7.35 \pm 0.93 \mathrm{hrs})$, it was found that there was statistically insignificant difference between these groups $(p>0.05)$. it might be due to mechanism of action of fentanyl both on peripheral nerves and dorsal nerve root when it is administered as an adjuvents (fentanyl may diffuse through brachial plexus sheath to extradural or subarachnoid space to dorsal horn) and central action on dorsal horn when administered systemically. Similar results have been reported by Kardas et al (1995). ${ }^{16}$

When compared Group C \& D, group C ie perineural clonidine had longer duration of analgesia $(\mathrm{p}$ $=0.006)$ compared to systemic clonidine group. Our findings corroborate by Singelyn et al (1992) ${ }^{17}$ and V. Bedi et al (2017). ${ }^{9}$

Mean VAS Score in present study remained less than 4 throughout the study period showing adequate postoperative analgesia in the all the four groups.

Overall value of mean VAS score was significantly more in group A $(1.88 \pm 0.13)$ as compared to group C $(1.33 \pm 0.22$ ). Thus perineural clonidine (group A) prolonged the rescue analgesia requirement compared to perineural fentanyl (group A). It indicated that clonidine was having good postoperative analgesia than fentanyl as a perineural adjuvent. Similar results have been reported by Baj et al (2013) ${ }^{1}$

Mean VAS score remained higher in group D $(1.65 \pm 0.14)$ as compared to group C $(1.33 \pm 0.22)$. Thus clonidine produced more prolonged postoperative analgesia when used as an adjuvents rather than intravenous administration with ropivacaine in Supraclavicular brachial plexus block. Iskandar et al $(2003)^{18}$ also supported our study and concluded that VAS score remained significantly lower in perineural group.

The incidence of nausea and vomiting was highest $(11.8 \%)$ in group B and was comparable in group A and group C (5.9\%) but statistically insignificant. Probably it may be due to systemically administered opioids stimulated chemoreceptor trigger zone that produce nausea and vomiting.

Incidence of sedation was more in group $\mathrm{D}$ (11.8\%) than in group C (5.9\%). Sedative properties of clonidine are attributable to this. Gaumann et $\mathrm{al}^{19}$ and Bernard $^{20}$ also found significant sedation with the use of clonidine than with plain LA showing similar result to our study.

\section{Conclusion}

Earliest onset of sensory and motor blockade as well as longer duration of analgesia resulted when clonidine $150 \mu \mathrm{g}$ was used as a perineural adjuvant to Ropivacane $0.75 \%$ with minimal side effects compared to its same dose given intravenously which proves that effect of clonidine is mediated locally rather than systemically; While fentanyl in Supraclavicular block as a perineural adjuvant or systemically administered having comparable results in duration of analgesia.

\section{Conflicts of Interest: None.}




\section{References}

1. Madhusudhana R, Kumar K, Kumar R, Potli S, Karthik D, Kapil M. Supraclavicular brachial plexus block with $0.75 \%$ ropivacaine and with additives tramadol, fentanyla comparative pilot study. Int J Boil Med Res. 2011;2(4):1061-1063.

2. Gaumann DM, Brunet PC, Jirounek P. Clonidine enhances the effect of lidocaine on $\mathrm{C}$ fiber action potential. Anesth Analg. 1992;74:719-725

3. Baj B, Tyagi V, Chaudhri R.S, Derashri A. A comparative study of effects of clonidine added to ropivacaine versus plain ropivacaine during supra clavicular brachial plexus block. J Evol Med Dent Sci. 2013;52:10228-10235.

4. Chandni M Soni, H Parikh. Comparision of the motor and sensory block by Ropivacaine and Bupivacaine in combination with Lignocaine in supraclavicular block. Natl J Medl Res. 2013;3(4).

5. Sarkar DJ, Khurana G, A Chaudhary, JP Sharma. A comparative study on the effects of adding fentanyl and buprenorphine to local anaesthetics in brachial plexus block. J Clin Diagn Res. 2010;4(6):3337-3343.

6. Carol A Bodian, Gordon Freedman, Sabera Hossain, James B. Eisenkraft, Yakob Beilin. The Visual Analog Scale for Pain, clinical significance in postoperative patients. Anaesthesiol. 2001;95:1356-1361.

7. Sia S, Lepri A. Clonidine administered, as an axillary block does not effect postoperative pain when given as the sole analgesic. Anesth Analg. 1999;88:1109-1112

8. Chakraborty S, Chakrabarti J. Mandai MC, Harza A, Das $\mathrm{S}$. Effect of clonidine as adjuvant in bupivacaine-induced supraclavicular brachial plexus block: A randomized controlled trial. Indian J Pharmacol. 2010;42:74-77.

9. Bedi V, Petkar J, Dindor B.K., Narang A, Tungaria H, Petkar K S : Perineural versus intravenous clonidine as an adjuvant to Bupivacaine in supraclavicular Brachial plexus block. Egypt J Anaesth. 2017;33:257-261.

10. Ahmed NU, Hossain M, Akhtaruzzaman AKM, Mondal MK, Khatun UHS. Addition of clonidine or fentanyl with bupivacaine for supraclavicular brachial plexus block in upper limb surgery-A randomized comparative study. $J$ Bangla Soc Anesthesiologist. 2011;24(1):3-7.

11. Kohli S, Kaur M, Sahoo S, Vajifdar H, Kohli P. Brachial plexus block: Comparison of two different doses of clonidine added to bupivacaine. J Anaesthesiology Clin Pharmacol. 2013;29(4):491-495.
12. Jaiswal R, Bansal T, Mehta S. A study to evaluate the effect of adding clonidine to ropivacaine for axillary plexus blockade. Asian J Pharm Clin Res. 2013;6(3):166168.

13. Eisenach JC, Dekock M, Klimscha W. Alpha (2) adrenergic agonists for regional anesthesia. A clinical review of clonidine (1984-1995). Anesthesiology. 1996;85:655-674.

14. Kulkarni, Tarkase AS, Chaudhary SA. Effect of addition of clonidine to bupivacaine in brachial plexus block. Pravara Med Rev. 2012;4.

15. El Saied AH, Steyn MP, Ansermino JM. Clonidine prolongs the effect of ropivacaine for axillary brachial plexus blockade. Can J Anaesth. 2000;47(10):962-967.

16. Kardash K, Schools A, Conception M. Effects of brachial plexus fentanyl on supraclavicular block. Reg Anesth 1995; 20:311-5.

17. Singelyn FJ, Dangoisse M, Bartholomee S, Gouverneur JM. Adding clonidine to mepivacaine prolongs the duration of anaesthesia and analgesia after axillary brachial plexus block. Anesth Analg. 1992;17:148-150.

18. Iskandar H, Benard A, Ruel-Raymond J, Cochard G, Manaud B. The analgesic effect of interscalene block using clonidine as an analgesic for shoulder arthroscopy. Anesth Analg 2003; 96:260-2.

19. Gaumann DM, Brunet PC, Jirounek P. Hyperpolarizing after potentials in $\mathrm{C}$ fibers and local anesthetic effects of clonidine and lidocaine. Pharmacol. 1994;48:21-90.

20. Bernard J-M, Kick O, Bonnet F. Comparison of intravenous and epidural clonidine for postoperative patient controlled-analgesia. Anesth Analg. 1995;81:706712.

How to cite this article: Meena $\mathrm{M} \mathrm{R}$, Tungria $\mathrm{H}$, Tyagi G, Banu A, Raiger L K. A prospective, randomized, doubleblind, systemic controlled trial to compare analgesic efficacy of clonidine and fentanyl in supraclavicular block with $0.75 \%$ ropivacaine. Indian $\mathbf{J}$ Clin Anaesth. 2018;5(4):518-522. 